\title{
Challenges of Sustainable Urban Development in the Context of Population Growth
}

\author{
By Constantin Marius Profiroiu ${ }^{1}$, Dumitru Alexandru Bodislav², Sorin Burlacu ${ }^{3}$, \\ Carmen Valentina Rădulescư
}

\begin{abstract}
Lately, we face many challenges that threaten the well-being of society and the quality of life. All of these challenges are complex and closely related, which means that one approach can have positive consequences for others. In this context, population growth, an extremely delicate subject, from a social and ethical point of view has generally become a threat to the entire planet, and in particular, to urban agglomerations. At the global level, population growth puts even greater pressure on basic resources, from fresh water to fertile land, endangering the very existence of humanity. The purpose of this paper is to analyze the population trend globally, as compared to the population trend in the big urban agglomerations, as well as the evolution of some indicators of the quality of life depending on the population growth. Following the analysis, we aim to identify various challenges and develop proposals for the sustainable development of urban space.
\end{abstract}

Keywords: Population, sustainable development, urban space

\section{Introduction}

The world's urban population has grown rapidly, from 751 million in 1950 to 4.2 billion in 2018. This growth has been mostly in Asia, despite the fact that the level of urbanization is relatively lower. Asia hosts $54 \%$ of the world's urban population, followed by Europe and Africa with 13\% each (UN, 2018).

The urbanization of countries and, implicitly of the population over time, has been influenced by many factors, among which we can mention: the stage and stages of development of agriculture, the industrialization of the country, the rate of population growth, the state of richness or poverty of a country.

Currently, the most urbanized regions include North America (with 82\% of the population living in urban areas), Latin America and the Caribbean (81\%), Europe (74\%) and Oceania (68\%). The level of urbanization in Asia is about $50 \%$. In contrast, Africa remains mostly rural, with $43 \%$ of the population living in urban areas (UN, 2018).

\section{Literature Review}

The literature abounds with models and examples of sustainable urban development. Some authors believe that despite some experiments, it is true that some urban areas are desensitized to the wider impact of environmental damage caused by residents and businesses and that there are various reasons for this, such as the level of 
information required, underdevelopment of reduction systems. the costs transferred or the introduction of compensation, the issue of legal limits and responsibilities in the field of environmental management, etc., and consequently, sustainable urban development requires changes in governance, market and regulation for both cities and nations (Haughton, 1997).

The proliferation of new digital technologies poses challenges in all areas. Urban development was no exception, so that cellular automata were widely applied to simulate and predict possible urban development. Some studies also offer an implementation of prototypes that can be used in urban planning by using different types of constraints that are associated with sustainable development criteria (Li \& Yeh, 2000) .

However, more and more research in the field of sustainable urban development considers that the complexity of the problem of sustainable development and the uncertainties about future development suggest that a key factor could be the construction of more robust and resilient cities. Otherwise, with the example of China, which has a high level of resource consumption, researchers suggest that cities will become like dinosaurs, unable to adapt to future problems, such as climate change and lack of resources, and due to increasing competition for resources. in the world, sudden political changes in countries and regions can drastically change the situation $(\mathrm{H}$. Liu et al., 2014).

Also following the example of China, other researchers have considered multidimensional deprivation in urban areas as an important measure for governmental and non-governmental organizations to identify the most disadvantaged urban areas. These studies view the concept of deprivation as a reference to specific conditions such as lower incomes, lack of clothing or housing, lack of housing, education and precarious social activities and consider that if there are various forms of deprivation, then people with these forms experience multiple deprivation (Yuan \& Wu, 2014).

But there are also studies that try to answer the question of whether sustainability and adaptability can be integrated into a single decision-making tool for the design of future buildings. The conclusions of this research demonstrate that the assessment of the future adaptation of newly designed buildings is feasible and further, these design criteria could be measured and developed in a design assessment tool, the adaptSTAR and ARP model, as an extension to existing sustainability tools used to measure the energy efficiency of the building, even going so far as to consider that integrability and adaptability into a single decision-making tool would be even possible (Conejos et al., 2014).

The issue of the effects of urbanization and climate change converging in dangerous ways and seriously threatening the sustainable development of the world is present in more and more research, highlighting the growing evidence of the pace of climate change globally. Remarkable are the results obtained which indicate that economic CO2 efficiency increases with increasing urban compactness, but that social CO2 efficiency decreases with increasing urban compactness and argue that policies that favor compact urban development can have positive effects on economic efficiencies and urban development should give priority to minimizing threats due to the unsuccessful use of non-sustainable resources (Y. Liu et al., 2014).

Looking back, more than 20 years ago, the concept of sustainable development is 
considered to be close to recognition, to disciplinary autonomy, becoming the focus of new theoretical and normative reflections and it was stressed that the same cannot be said. about a more specific field of application of the same concept - the urban environment. According to the authors, this was hindered by some unresolved issues definition, methodology and epistemology - intrinsic to the more general concept, but also by certain specificities of the urban case that were not sufficiently taken into account. Studies of those times considered that a city is, by nature, a manufacture, an object almost entirely artificial, built for historical purposes of socialization, synergy, growth of knowledge and social welfare (Camagni, 1998).

\section{Findings}

Today, $55 \%$ of the world's population lives in urban areas, a proportion that is expected to grow to $68 \%$ by 2050 . Projections show that urbanization, the gradual shift of human population from rural to urban areas, combined with the world's population growth It could add another 2.5 billion people in urban areas by 2050 , with almost $90 \%$ of this growth taking place in Asia and Africa, according to the United Nations (2018).

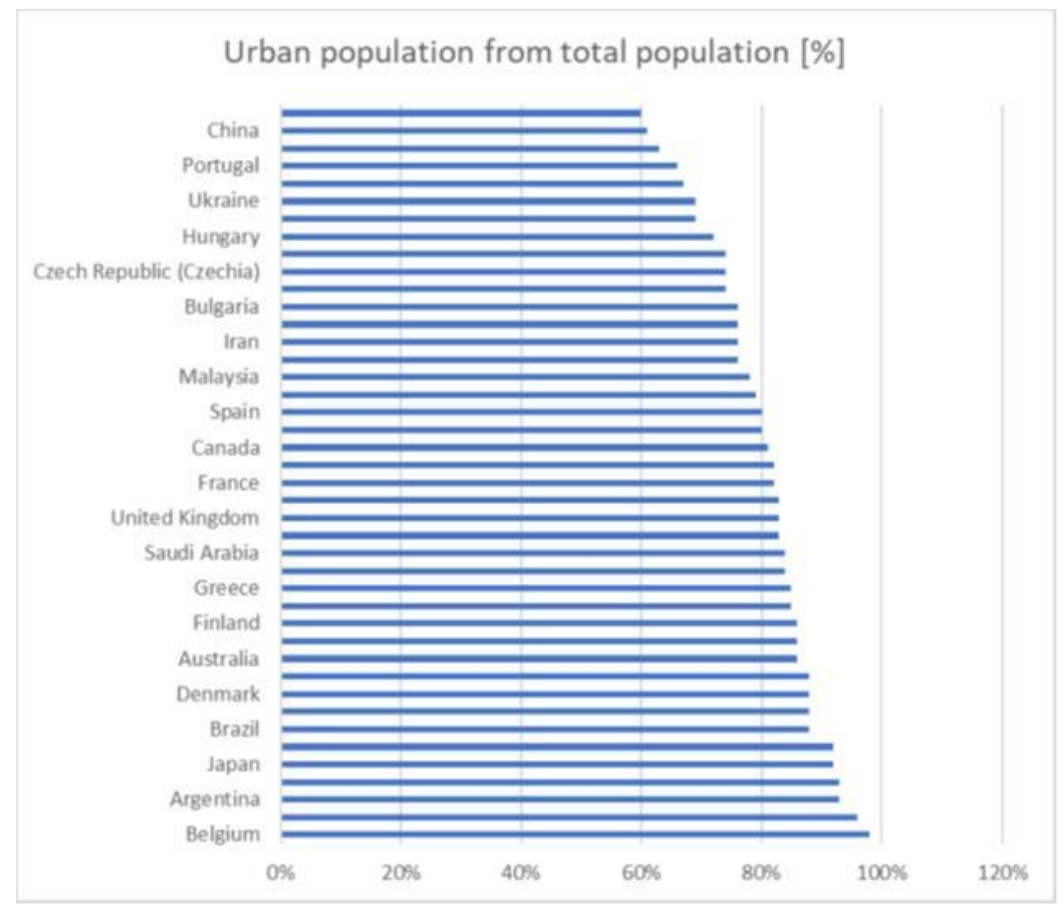

Fig. no. 1 Urban population from total population [\%]

Source: bttps:/ / www.worldometers.info/world-population/population-by-country/

\section{Population Declines in Some Cities}

Some cities have experienced a decline in population in recent years. Most of 
them are located either in countries with low fertility agriculture in Asia or in Europe, where the total population size is stagnant or declining due to population migration to countries or cities where they have found better paying jobs. Economic contraction and natural disasters have also contributed to the loss of population in some cities.

Several cities in Japan and the Republic of Korea (for example, Nagasaki and Busan) experienced a decline in population between 2000 and 2018. Several cities in Eastern European countries, such as Poland, Romania, Russia and Ukraine, have lost a large share. from the population starting with 2000 and up to the present.

As mentioned above, emigration has also contributed to the smaller population size in some of these cities.

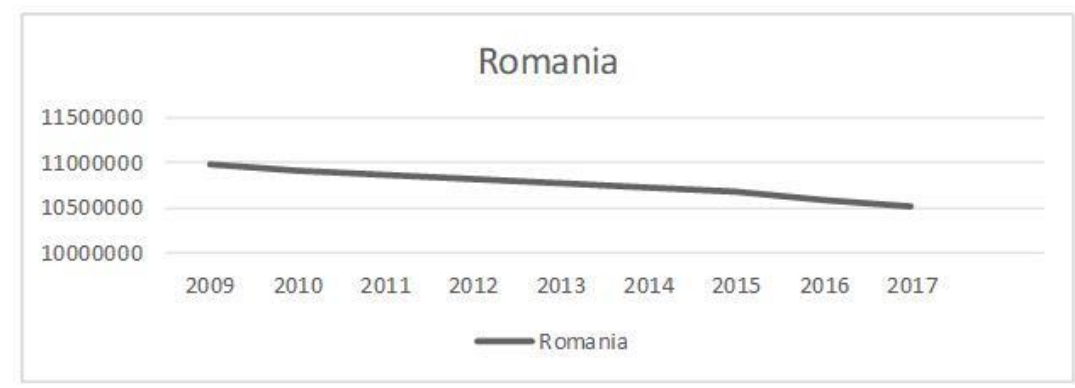

Fig. no. 2 Urban population decline in Romania

Source: http:/ / data.un.org

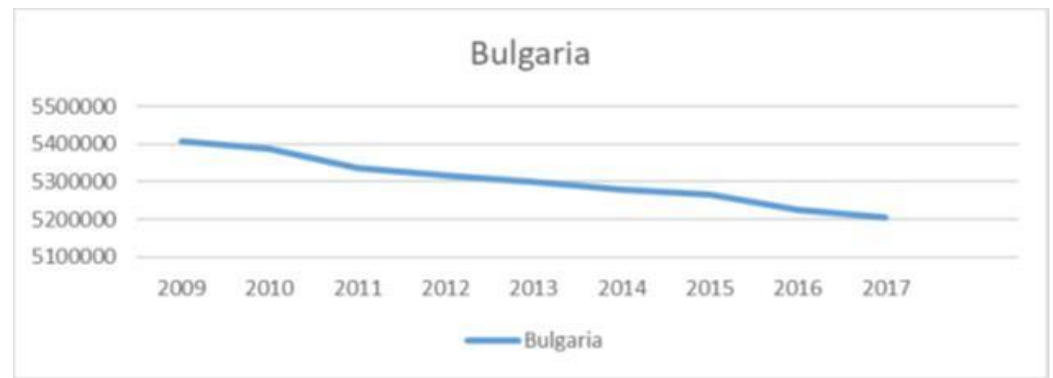

Fig. no. 3. Urban population decline in Bulgaria

Source: http:/ / data.un.org

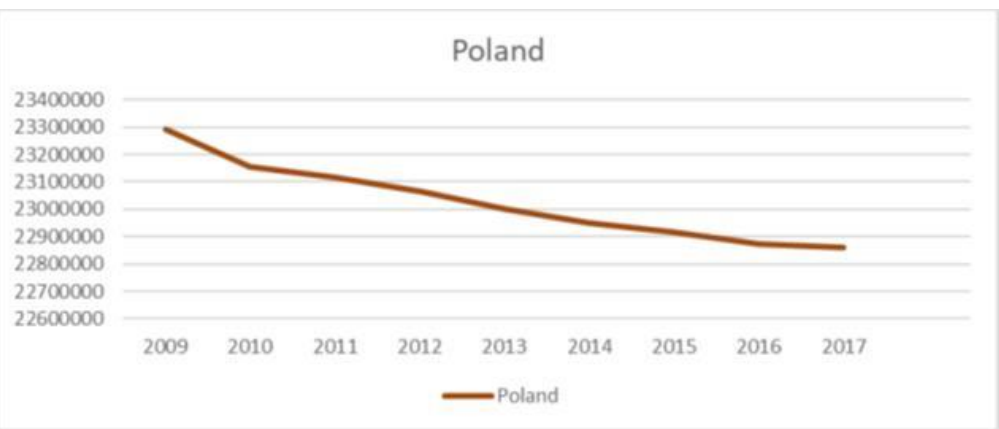

Fig. no. 4 Urban population decline in Poland 
Source: http:/ / data.un.org

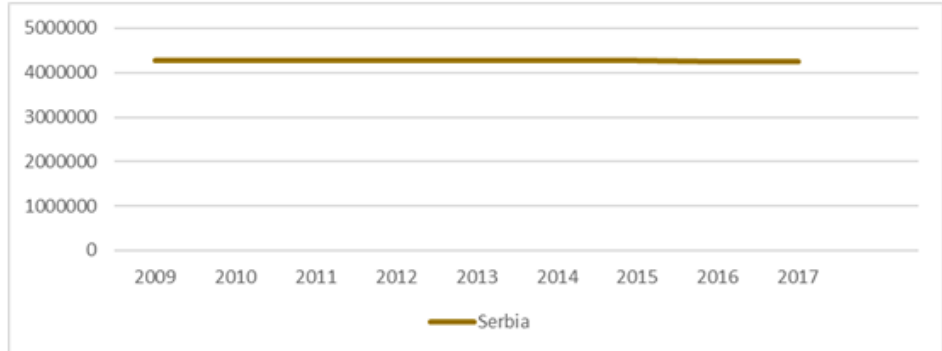

Fig. no. 5 Urban population decline in Serbia

Source: http:/ / data.un.org

\section{Population Growth in High-Ranking Cities or Mega Cities}

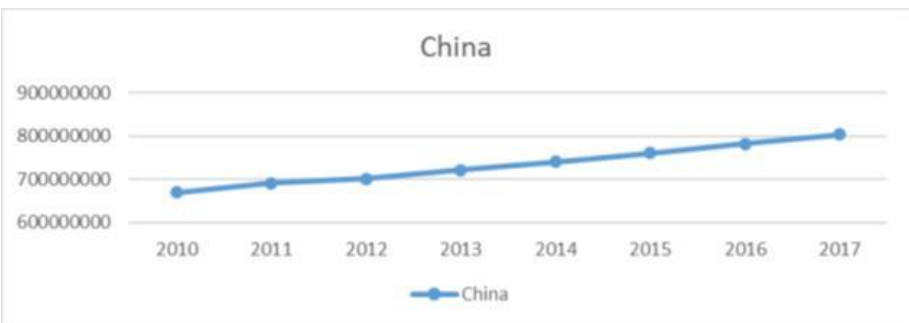

Fig. no. 6 Urban population growth in China

Source: http:/ / data.un.org

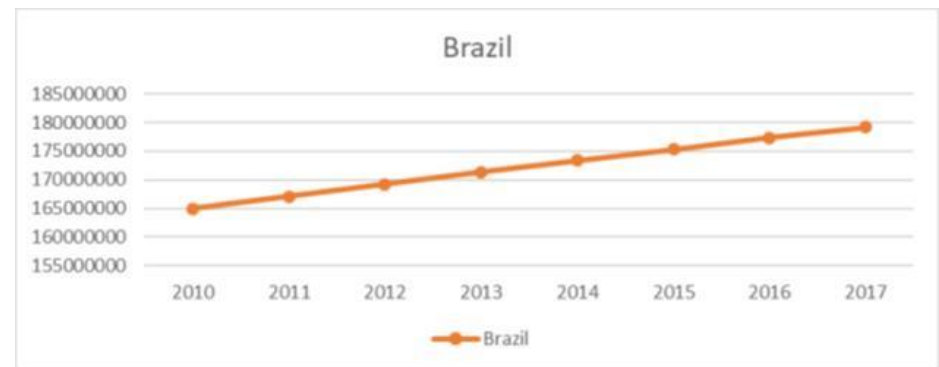

Fig. no. 7 Urban population growth in Brazil

Source: http:/ / data.un.org

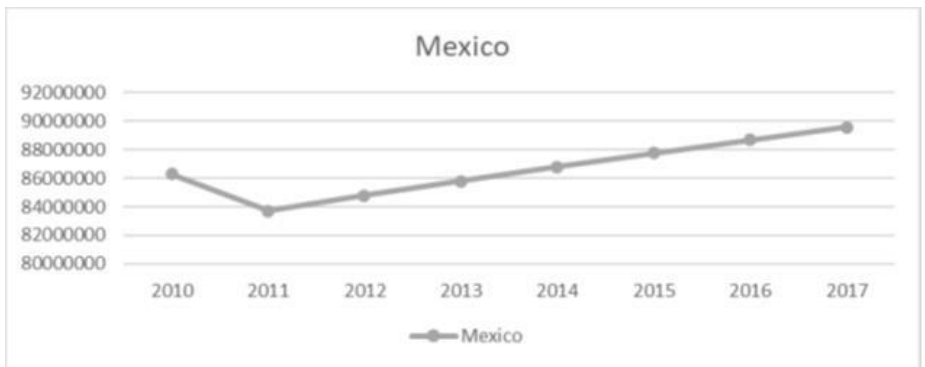

Fig. no. 8 Urban population growth in Mexico 
Source: http:/ / data.un.org

Tokyo is the largest city in the world with a crowd of 37 million, followed by New Delhi with 29 million, Shanghai with 26 million, and Mexico City and São Paulo, each with approximately 22 million inhabitants. Today, Cairo, Mumbai, Beijing and Dhaka have nearly 20 million inhabitants. By 2020, it is estimated that Tokyo's population will begin to decline, while Delhi will continue to grow and become the world's most populous city by 2028 .

By 2030, the world will have 43 mega cities with over 10 million inhabitants, the majority in developing regions. However, some of the fastest growing urban agglomerations are cities with less than 1 million inhabitants, many of them located in Asia and Africa. While one in eight people lives in 33 mega cities around the world, nearly half of the world's urban dwellers live in much smaller settlements, with fewer than 500,000 inhabitants.

\section{Strategic Options for Sustainable Urban Development}

As the world continues to urbanize, sustainable development is increasingly dependent on successful urban growth management, especially in low- and middleincome countries, where urbanization is projected to be the fastest.

Many countries will face challenges to meet the needs of their growing urban populations, including housing, transportation, energy systems and other infrastructure, as well as employment and basic services, such as education and health.

Integrated policies are needed to improve the lives of urban and rural residents, while strengthening the links between urban and rural areas, based on their existing economic, social and environmental links.

\section{Conclusions}

To ensure that the benefits of urbanization are fully shared and inclusive, urban growth management policies must ensure access to infrastructure and social services for all, focusing on the needs of the city's poor and other vulnerable groups for housing, education, care medical, decent work and a safe environment.

And as we stated in the opening of the paper, even if lately we face many challenges that threaten the well-being of society and quality of life, all these challenges are complex and closely linked, which means that one approach can have positive consequences for others. In this context, I highlighted, studying the literature but also practically, through analyzes and case studies, that population growth is an extremely delicate subject from a social and ethical point of view.

Today, this subject, in the context of the new conditions imposed by the pandemic that has engulfed us, has become a threat to the entire planet and, in particular, to urban agglomerations. Globally, population growth puts even greater pressure on basic resources, from freshwater to fertile land, endangering the very existence of humanity and social distancing, as a solution imposed by the authorities in crisis situations only comes to solve a punctual, sanitary problem and not a fundamental economic-social one. 


\section{References}

Camagni, R. (1998). Sustainable urban development: definition and reasons for a research programme. International Journal of Environment and Pollution, 10(1), 6-27. https://doi.org/10.1504/IJEP.1998.002228

Conejos, S., Langston, C., \& Smith, J. (2014). Designing for better building adaptability: A comparison of adaptSTAR and ARP models. Habitat International, 41, 85-91. https://doi.org/10.1016/j.habitatint.2013.07.002

Haughton, G. (1997). Developing sustainable urban development models. Cities, 14(4), $189-195$. https://doi.org/10.1016/s0264-2751(97)00002-4

Li, X., \& Yeh, A. G. O. (2000). Modelling sustainable urban development by the integration of constrained cellular automata and GIS. International Journal of Geographical Information Science, 14(2), 131-152. https://doi.org/10.1080/136588100240886

Liu, H., Zhou, G., Wennersten, R., \& Frostell, B. (2014). Analysis of sustainable urban development approaches in China. Habitat International, 41, 24-32. https://doi.org/10.1016/j.habitatint.2013.06.005

Liu, Y., Song, Y., \& Song, X. (2014). An empirical study on the relationship between urban compactness and CO2 efficiency in China. Habitat International, 41, 92-98. https:/ / doi.org/10.1016/j.habitatint.2013.07.005

Yuan, Y., \& Wu, F. (2014). The development of the index of multiple deprivations from small-area population census in the city of Guangzhou, PRC. Habitat International, 41, 142-149. https://doi.org/10.1016/j.habitatint.2013.07.010

United Nations, Department of Economic and Social Affairs (2018), 68\% of the world population projected to live in urban areas by 2050, says UN, ww.un.org/development/desa/en/news/population/2018-revisionof-world-urbanization-prospects.html http://data.un.org/Data.aspx?d=POP\&f=tableCode $\% 3 a 1$ 